\title{
Exploring the Decision to Volunteer Online in Health Virtual Community
}

\author{
Norzaila Mohamad Nor ${ }^{1}$, Nafishah Othman ${ }^{2}$ and Shafiz Affendi Mohd Yusof ${ }^{3}$ \\ ${ }^{1}$ Kulliyyah Muamalat dan Sains Pengurusan, UniSHAMS, Kedah, Malaysia, \\ ${ }^{2}$ College of Arts and Sciences, UUM, Sintok, Malaysia, \\ ${ }^{3}$ Faculty of Engineering and Information Sciences, University of Wollongong in Dubai, UAE
}

\begin{abstract}
This paper is part of ongoing research seeking to explore why doctors volunteering online through health virtual community (HVC). Although many studies have investigated the reasons individual volunteer online, there has been scant research on the decision that influence doctors to participate online via HVC. Here, researchers report on the factors that influence doctors to volunteer online in HVC as the doctor's heavy workload may postulated source of work-family conflict. A qualitative case study approach was used to explore and understand why doctors volunteering online in a HVC called DoktorBudak.com (DB). Seventeen semi-structured interviews were conducted with pediatricians and pediatricians related specialists. Important factors related to technological and human aspects were identified. Factors were related to information and communication technology (ICT), knowledge sharing, peers influence and rewards. This qualitative study offer some unique insights about factors affecting doctors volunteering online in HVC, which were rarely addressed in the existing literature of online volunteer. Since the healthcare system is undergoing the digitalization revolution through the inception of the HVCs, this study had discussed the factors that must be in place for digital systems to be operative.
\end{abstract}

Key words: Doctors, Health Virtual Community, Volunteering Online

\section{INTRODUCTION}

Proliferation of health demands emerging from a deficiency of health resources have become an emergent global concern, with information and communication technologies (ICTs) considered as vital solutions for this problem [1]. According to the mid-term review of the Eleventh Malaysia Plan 20162020 [2], a number of key challenges need to be addressed by the government in providing a better healthcare services at affordable cost to the citizens. These include rising demand for better healthcare services, shortage of healthcare personnel and inadequate health facilities to deliver the health promotion services. In addressing the lacking number of healthcare personnel (e.g. doctors, medical specialists); alternative mechanisms were proposed [2] to deliver the healthcare services through online such as via health virtual community (HVC). By leveraging the technologies and social media networks, healthcare professionals established a better formula with minimal cost to aid government. In addition, greater collaboration and participation between the government and the non-governmental organizations (NGOs), private sector as well as volunteers organizations may create a more sustainable healthcare system.

In general, HVCs enable its stakeholders and participants, such as doctors and patients to interact virtually by sharing their knowledge and experience or provide support to the virtual communities [3][4][5]. HVCs also provide a means for patients in meeting their social needs [6][7][8] and empower them to manage their own healthcare [9][10].

However, rapid developments in Internet technology have changed the nature of work for doctors volunteering online in HVC. The smart phone and Web 2.0 tools (i.e. blogs, social networking sites) has facilitated doctors volunteering online tasks and allow for flexibility to take place, thus help them to combine their work and non-work responsibilities [11]. Conversely, the technology use at work or home has established further opportunities for interrole conflicts through increased combination of roles 


\section{Norzaila / International Journal of Business and Management, 3(5) 2019, Pages: 11-18}

[12][13] such as employee, spouse, parent and online volunteer. These issues, coupled with the fact that the nature of doctors' work which requires long working hours, the need for $24 / 7$ access to the medical service and heavy workload [14] has actually pose other new challenges for doctors volunteering online as it involves their time and effort [15].

A study by [16] reported that doctor's responsibilities and constraint related to their job has been a problem for them in providing patient in HVCs better online medical services. Furthermore, $19 \%$ of major HVCs moderated by doctors showing potential limitations in time [17]. Given these phenomenon, it is important to deeply understand why doctors volunteer online despite all of the challenges they are facing with regardless their work or family.

The rest of this paper is organised as follows: First, we reviews the relevant literatures on reasons why individual volunteer online. Second, we present the methodology used to carry out the study. The methodology includes the type of study, data collection procedures and data analysis process. Third, we discuss the themes identified as a result from the study. Finally, we close with discussion and conclusion of the study.

\section{LITERATURE REVIEWS}

Many individuals use online volunteering as a means for learning opportunity, others to develop skills that may enhance their paid positions. Some people volunteer online because it provides them with the opportunity to help others [18]. Some volunteer online because it gave them more choices in regards to selection of the cause, organization, and location for volunteering [19]. Others volunteer as a way to gain access to inaccessible information that is relevant to their work, and still others motivated to volunteer because of social behavior, where the more people they know in real world, the more they feel attached to the virtual community [20].

In the literatures of human behavior, [21] has previously undertaken research into the 'Zoouniverse' projects where online volunteer contribute their skills to online project to feel better about themselves, gain new learning perspectives, to express personal values as well as to shield themselves from problems. [22] also discover that regular communication between managers and participants as the main motivational element behind participation in online volunteering projects.

A case study by [23] on seven non-profit organizations in Vancouver revealed that the medium of the volunteering itself defines whether individual are interested in volunteering or not. She stated that those who allocate most of their time on the Internet are expected to volunteer online. However, it is probably fair to say that the finding above fits to another individual but not to doctors.

In an online healthcare context, many of the literature study doctors' motive towards the use of social media for health-related purpose. For example, survey by [24] reported that European radiologist is motivated to engage in social media to share information while [25] claimed that doctors use social media for professional networking and marketing. Study by [26] demonstrates that doctor join an intensive care practice-based Virtual Community of Practice (VCoP) to enhance their professional networks, access valuable knowledge, improve clinical practice and indirectly improves patient outcomes. Furthermore, as the majority of existing studies on volunteer reason has mostly focused on onsite volunteering activities; it is of utmost important to develop a more detailed understanding of the doctors' decision to volunteer online.

Generally, previous research offers useful background, but no definite answers to the questions this study try to address, since there are significant variances between doctors' motivations participation in HVC and participation in other types of virtual community based projects. Principally, the nature of volunteering online in $\mathrm{HVC}$ is very different from involvement in other virtual community-based projects, for example Wikipedia where it is mostly passive and involves connecting to the computing resources only. In contrast, in other community-based projects participants actively contribute their skills, knowledge, and time.

[16] suggest that the main reasons doctor volunteer in a HVCs include altruism, knowledge sharing and for career enhancement opportunities. Other factors include opportunity to enhance their professional networks, access valuable knowledge and improve clinical practice [26]. This study try to explore other factors that may influence doctors to volunteer online in HVCs.

\section{METHODOLOGY}

\section{Case Study: DoktorBudak.com (DB)}

This study used a case study to explore the reasons that influence doctors to volunteer online in one of the most appealing and unique Health Virtual Community (HVC) in Malaysia; DoktorBudak.com. A case study using a qualitative approached was used to generate an in-depth understanding of the experiences of doctors in deciding to volunteer online. This HVC aims at aiding parents and sharing 
knowledge with them by creating an online channel to respond to children's health-related issues about. The members of the community are volunteers of pediatricians and pediatric-related specialists who work in the government and private hospitals all over Malaysia. DoktorBudak online volunteers offer a potential solution to some problems in the health system in Malaysia, such as the inadequate number of health promotion workforce, lack of supportive environment, and the unwillingness of the community to take ownership of health issues.

\section{Data Collection Procedures}

A mixed of purposive and snowball sampling strategy was used to recruit DoktorBudak (DB) team members. Researcher contacted and get consent from the DB founder to identified those doctors who were willing to participate in the study. Seventeen pediatricians and pediatric-related specialists agreed to participate in this interview to explore reasons they volunteer online in HVC. Participants came from doctors employed in government and private hospital and had joined DB since its inception.

The data were collected through in-depth, semistructured interviews. Before interviewing began, researcher explained the objectives of the study and their right as participants. Since the doctors have a hectic schedule to participate in the study, only two of them were managed to be interviewed face-to-face. Other participants responded through email, Skype and telephone call. The interviewer prepares an interview protocol in advance, consisting of two parts, with the aim of prompting interviewees' thoughts about their reasons to volunteer online. In the first part of the interview, respondents were asked to provide background of their work and family in order to understand better the nature of their work and family. In the second part, each respondent was asked about their involvement as online volunteer, the passion and reasons they volunteer online in a DB HVC. Finally, the interview questions were concluded by asking respondents to reveal the challenges in using the ICT to accommodate both work and family activities.

\section{Data analysis}

Audio recordings of the interview were transcribed verbatim after each session. Thematic data analysis was used to analyze the findings, which involves the process of identifying, analyzing and reporting patterns from responses or data. First, the researcher read the transcriptions while listening to the audio recording repeatedly to be fully immersed in the data and to acquire a detailed understanding of the data. Then, the researcher identified the first order construct or in-vivo codes in creating new codes (e.g., given the statement "I am excited when the article comes out, ooo its ok, there is our article. Then, when someone else shares, we feel like selfmotivated. It's like rewarding and satisfying me. And it's a pleasure to help others." [R2], the term "reward" is used as a code). Next, the second-order construct was identified. A second-order construct is created by the researcher using her theoretical and own knowledge. In the next step, a major concept or themes were created based on the responses of each participant. The codes and categories developed in previous steps were reviewed several times against the research question to determine the main themes of the study. The coding process stops when no new themes emerge.

After all themes have been identified, verification and validation of the results were performed through triangulation and member checking. Researcher put emphasis on triangulation by using various sources of evidence for data (e.g. from document reviews and observing online messages from DB social media platform), in which the weakness of one source of data (e.g. from interviews) can be overcome by the strength of another source of data. Meanwhile, through member checking process, four out of the seventeen respondents $(24 \%)$ replied and confirm that the findings drawn from the interviews reflect what was meant by them. By engaging respondents in the member checking process, it increase credibility to the study by having the opportunity to respond to the data and the final narrative. Many researchers agree that triangulation and member checking is a good way to enhance the credibility and validity of qualitative research [27][28][29][30].

\section{RESULTS}

Four themes emerged from the findings that explained the respondent's reason to volunteer online via HVC. The main themes were ICT related factors, knowledge sharing, peers and rewards.

\section{ICT Related Factors}

Results of the study showed that, in general, doctors believed that ICT factors namely perceived usefulness and ease of use influence them to volunteer online through HVC. Perceived ease of use refers to the extent to which respondents believe that it is easy to use the ICT tools for volunteering purpose. In this regard, respondents reported that they chooses to volunteer online because the platform makes it possible for them to perform volunteering task from anywhere at any time. This is supported by doctor statements such as the following: 
"One, because online is easy, that means you can access it anywhere you want, be at home, be at work" [R7]

Despite having limited times with their job, some of the respondents interviewed noted that it is much easier for them to find ways to volunteer their time as everything is virtual these days. They tried to spend their best time for several minutes or hours in a day or depending on their free time. As one respondent said:

“'It's easy as everyone is on virtual these days" [R9]

While respondents were conscious of their role as doctors and parental responsibility, a few respondents described that it is not difficult or timeconsuming to volunteer online as answered by one respondent,

"First because online is easy, means you can access it while at home at work, you can actually do your volunteer work at home. So it doesn't take much of my time, because it is very flexible. You can write your article whenever you want" [R6]

They tried as best as they can to allocate time for several minutes or hours in a day or depending on their free time to perform the volunteering works.

\section{Peers Influence}

Peers influence refers to the decision doctors to involve in volunteering are strongly inspired by peers or colleagues. Most of the respondents reported that they had been approached by their colleagues, former colleagues or friends to volunteer online. Some of the respondents stated that volunteer because they were invited by their senior back in University or senior during their high schools. One of the respondents stated:

"Personally, I was approached by Dr..A because we used to work in the same hospital, and I'm no longer there" [R10]

Other than that, some of the respondents mentioned that they were approached by their peers with a request to participate with the DB because of their specialty area. This was illustrated well by the respondents:

"Because actually my interest apart from doing ofptal, is talking about lactation, about parenting. So that's why I join DB, I was invited by Dr. A, because of my active participation in lactation awareness programmes" [R6]

\section{Knowledge Sharing}

In-depth interviews, observation on social media and documents review indicated that knowledge sharing was one of the main factors that influence the willingness of doctor to volunteer online in a HVC. Respondents expressed the theme, sharing knowledge from many viewpoints. Most of the respondents tended to describe their enthusiasm in sharing not only their expertise in medical practice, but their experience as well. By volunteering in online platform, it would be easier for them to share knowledge with the public. One of the respondents mentioned:

"I like to share things that I deal with every day at home" [R7]

With respect to sharing knowledge via HVC, the findings were almost unanimous: most of the doctors felt obligated to share something beneficial in terms of controlling the spread of misinformation and correcting people perception particularly on health issues:

"Sense of responsibility to share and disseminate useful medical knowledge to the public. Too much false information or myths circulating around and we as the so called experts have to do something about it. " [R12]

"The need to share and spread the truth about child health and to eliminate all the myths surrounding it." [R4]

"I love to share my knowledge to the mass people since Malaysian parents seems to have few information regarding their child health and some of them have resorted to finding information online. However some of the information given on-line are not true" [R5]

Many respondents demonstrated their responsibility in sharing information by helping the public generally and parents, in particular, in assisting them to determine 'right action' when handles their children's health. As one respondent phrased it:

"So I want to share basic information about child health that would help parents to understand more about their children's health, so that they would 
make the right decisions and not unnecessarily anxious" [R15]

Another related aspect of sharing knowledge by respondents was influenced by the social media usage. It is clear that respondents passionate about patient's health plus with their strong interest in social media have led them to share knowledge with the public. As one respondents write:

"I loved the blog, and I want to write something useful to share with the public, instead of just personal issues and political opinions." [R1]

"A platform that I can reach the public in order to share and educate them besides during my daily practice. And I love doing it." [R13]

The data from this study also indicated that the respondent willingness to share their knowledge with the public via HVC stemmed from the feeling that the public especially parents should have understand more about their children's health in order to help them take their own decisions. With that, the respondents believe that they are empowering the community by sharing their knowledge and experiences, hoping to improve the community for betterment.

\section{Rewards}

The respondents discussed how the rewards they received keeping them volunteering online while maintaining other commitment in their life. All of the respondents identified intrinsic derived rewards, such as feeling appreciated and enjoying one's role. The respondents stated that these rewards were provided by simple recognition from parents or readers who read the article they published. Indeed, such rewards were commonly expressed as selfmotivation for them. In one of the interview, one of the respondents shared that she feels appreciated when her articles being shared by the online readers. She stated,

"I am excited when the article comes out, ooo its ok, there is our article. Then, when someone else shares, we feel like self-motivated. It's like rewarding and satisfying me. And it's a pleasure to help others." [R2]

One of the respondent reported feelings overwhelmed knowing that readers out there have actually read their post on DB, benefit from it and applied it in their real life. One of the respondents expressed her feeling as:
"The child was just discharged home and when they wrote to us, we suggested to do, you know, a decent things, to go to the hospital ... it found out that it was indeed infection in the brain, so I think that was one of the earliest motivation for us ... and I actually kind of having what is called that, a rewarding feelings to us". [R3]

Respondents, however, also identified another forms of intrinsic rewards, for example associated with rewards received from God, as being significant factors in engaging with volunteering online. One of the respondents when asked on how she motivates herself to volunteer online while having multiple commitments and competing demands explained:

"First is because of the pahala (reward) I can get, for the life hereafter. It is platform for me to contribute. Then, it is not about recognition or respect. But as a Muslim of course you are motivated to do good deeds to seek the pleasure of Allah. When I spread, I share the knowledge, I get pahala (reward) in return and I may get the advantage in this world as well the hereafter" [R7]

Furthermore, several participants highlighted that this form of reward drives towards in giving back to the community and caring for those in need.

"I like to think it as God's reward. Because when you go and see the Specialist, you have to pay for it right? So by doing something online take it my time off from my hectic schedule ... I hope when people read the article, you know, I do get rewards from it. Part of my charity work" [R6]

\section{DISCUSSION AND CONCLUSION}

[31] suggest that factors that promote technology use in any healthcare sectors are technological and human. The technology aspects mentioned may include the adoption of health virtual community leveraged by doctors that influence them to volunteer online. Consistent with past researchers finding, other factors relates to altruistic, knowledge sharing and values also serve as a central driver for volunteering online in virtual community [21][1][32].

In this study, researchers found that doctors perceived usefulness of the technology (e.g. Web 2.0 technologies and social media) and the attitudes doctors have toward the value these technologies provide, influence doctors to participate in the HVC. Before carrying out the study, researchers believe 


\section{Norzaila / International Journal of Business and Management, 3(5) 2019, Pages: 11-18}

that participated doctors will show negative attitude toward online volunteering, possibly because of job commitment and burden. They might perceive online volunteering as adding another burden and new roles to their current work-family life. This turned out not to be true.

From the technological viewpoint, online volunteering via HVC offers many benefits to the doctors. The ICT related factors allow doctors to access online easily and beneficial for their online volunteering activities while performing other workfamily activities. Despite time, mobility, or other barriers (e.g. high workload) that have kept them from doing so, volunteering online has open up many opportunities for doctors to contribute to the society. These online technologies also have facilitated doctors volunteering online to share knowledge, medical experience, best practices as well as curbing spread of misinformation related to children healthcare.

In addition to technological factors, another reason identified in why doctors were influence to volunteer online is the human related aspects. [33] agreed that peers especially high-status peers also play important roles in influencing individual to volunteer. In this study, peers refers to the founder and co-founder of the DB HVC who mostly affect the decision for other team member to participate in the same HVC. The findings suggested that peers influence not only depends on sharing similar interest but also on trust, credibility and leadership that binds the community together. This result is consistent with the findings reported by [34] and [35] who found that trust in virtual communities is developed through traditional personal contact and physical interaction. Apart from that, the capacity to be with experienced and influential peers in the same virtual community was important in accessing the decision-making and learning process within the shared knowledge of their peer doctors in order to improve the quality of patient care especially in a different specialize areas that may complement each other. Researcher also believed that the decision made by respondents in this study to be with their peer, colleague or long-known friend who shared similar working condition is part of important process in sustaining good HVCs.

Furthermore, our results also revealed that intrinsic reward such as feeling appreciated of one's role, concern for others and serving to help do serve as another key factors for volunteering. This study suggests that respondents feel rewarded through feelings of appreciation and personal satisfaction gained when the online readers valued their contribution (such as when receiving responses from others). The respondents enjoyed the rewarding feelings when the knowledge shared through the HVC has empowered readers (e.g. parents and public) and added perceived value to the reader's experience of care. Another form of reward received by doctors volunteering online are reward received from God specifically in the live hereafter. It is clear that any religion cares for the welfare of all humans and ask its members to engage in volunteer works without hoping for any reward form the God. [36] and [37] highlighted the 'religion' theme was important in determining the decision to volunteer. Religiosity refers to the importance individuals attached to any beliefs practices of religion. The findings of this study shows a few of the respondent's reason come from a strong belief in God's reward and devoted to service others due to religious responsibilities. They did not expect any recognition or respect in return for their work, yet knowing the virtual communities benefited the knowledge shared has actually reflected respect and appreciation.

Given the constructive link of all the factors, researchers conclude that opportunities for doctors volunteering online in HVC seem to represent the current factor to volunteer in this virtual environment. It thus appears that online volunteering for doctors possibly concerned more on the technological aspect as well as the human aspects, more than the traditional methods of volunteering. The discussed characteristics may be the key to attaining cooperative health virtual community in the longer period involving doctorspatients communications. By volunteering online, it is seems realistic to presume that virtual communities open up new avenues for interaction and will grow to meet the ever expanding interest of many parties such as doctors, patients and the hospital.

\section{REFERENCES}

[1] Guo, S., Guo, X., Fang, Y., Vogel, D. (2017). How doctors gain social and economic returns in online health-care communities: A professional capital perspective. Journal of Management Information Systems, 34(2), 487-519.

[2] Ministry of Economic Affairs, S. (2018). Midterm review of the Eleventh Malaysia Plan 20162020: New priorities and emphases. [online] Talentcorp.com.my. Available at: https://www.talentcorp.com.my/clients/TalentCorp _2016_7A6571AE-D9D0-4175-B35D-99EC514F 2D24/contentms/img/publication/Mid-Term Review of 11th Malaysia Plan.pdf [Accessed 8 Oct. 2019] 
[3] Mpinganjira, M. (2019). Willingness to reciprocate in virtual health communities: The role of social capital, gratitude and indebtedness. Service Business, 13(2), 269-287.

[4] Peng, X., Sun, D., Zhao, Y., \& Xu, W. (2015). What trigger people use physician-patient interactive ohcs? An empirical research based. Paper presented at the The Pacific Asia Conference on Information Systems (PACIS). Retrieved from http://aisel.aisnet.org/cgi/viewcontent.cgi?article $=1$ 254\&context $=$ pacis 2015

[5] Huang, K. Y., Chengalur-Smith, I., \& Pinsonneault, A. (2019). Sharing Is Caring: Social Support Provision and Companionship Activities in Healthcare Virtual Support Communities. MIS Quarterly, 43(2).

[6] Boling, B., Hart, A., Chizimuzo, T., Okoli, C., Halcomb, T., \& El-mallakh, P. (2015). Use of social media as a virtual community and support group by left ventricular assist device (LVAD) patients, The VAD Journal, 1(18), 1-15.

[7] Sharma, S., \& Khadka, A. (2019). Role of empowerment and sense of community on online social health support group. Information Technology \& People.

[8] Wang, X., Zuo, Z., \& Zhao, K. (2015). The evolution of user roles in online health communities - a social support perspective. In Pacific Asia Conference on Information Systems (PACIS 2015). [9] Morr, C. E. (2010). Challenges and opportunities health care virtual communities. In M.M CruzCunha, A.J. Tavares, \& R. Simoes (Eds.), Handbook of Research on Developments in e-Health and Telemedicine: Technological and Social Perspectives (pp. 278-298). Hershey, Pennsylvania: Medical Information Science Reference

[10] Morr, C. El, Cole, C., \& Perl, J. (2014). A health virtual community for patients with chronic kidney disease. Procedia Computer Science, 37, 333-339.

[11] Allen, T. D., Johnson, R. C., Kiburz, K. M., \& Shockley, K. M. (2013). Work-family conflict and flexible work arrangements: Deconstructing flexibility. Personnel Psychology, 66(2), 345-376. doi:10.1111/peps.12012

[12] Konig, C. J., \& De La Guardia, M. E. C. (2014). Exploring the positive side of personal internet use at work: Does it help in managing the border between work and nonwork?. Computers in Human Behavior, 30, 355-360.

[13] Wet, W. de, \& Koekemoer, E. (2016). The increased use of information and communication technology (ICT) among employees: Implications for work-life interaction. South African Journal of Economic and Management Sciences, 19(2), 264281.

[14] Gyorffy, Z., Dweik, D., \& Girasek, E. (2016). Workload, mental health and burnout indicators among female physicians. Human Resources for Health, 14(1), 12. http://doi.org/10. 1186/s12960016-0108-9

[15] Gang, K., \& Ravichandran, T. (2015). Exploring the determinants of knowledge exchange in virtual communities. Engineering Management, IEEE Transactions on, 62(1), 89-99.

[16] Atanasova, S., Kamin, T., \& Petric, G. (2017). Exploring the benefits and challenges of health professionals' participation in online health communities: Emergence of (dis) empowerment processes and outcomes. International Journal of Medical Informatics, 98, 13-21.

[17] Huh, J., Patel, R., \& Pratt, W. (2012). Tackling dilemmas in supporting the whole person in online patient communities. In Proceedings of the SIGCHI Conference on Human Factors in Computing Systems (pp. 923-926). ACM.

[18] Baruch, A., May, A., \& Yu, D. (2016). The motivations, enablers and barriers for voluntary participation in an online crowdsourcing platform. Computers in Human Behavior, 64, 923-931. http://doi.org/10.1016/j.chb.2016.07.039

[19] Mukherjee, D. (2010). Participation of older adults in virtual volunteering: A qualitative analysis. Ageing International, 36(2), 253-266.

[20] Butler, B., Sproull, L., Kiesler, S., \& Kraut, R. (2005). Community building in online communities: Who does the work and why. Leadership at a Distance. Lawrence Erlbaum Publishers, Inc., Mahwah, NJ.

[21] Cox, J., Oh, E. Y., Simmons, B., Graham, G., Greenhill, A., Lintott, C., \& Woodcock, J. (2018). Doing good online: The changing relationships between motivations, activity, and retention among online volunteers. Nonprofit and Voluntary Sector Quarterly, 47(5), 1031-1056.

[22] Dhebar, B. B., \& Stokes, B. (2008). A nonprofit manager's guide to online volunteering. Nonprofit Management and Leadership, 18(4), 497-506.

[23] McsKimming, Y. R. (2015). Virtual volunteering in social service non-profit organizations: a case study. Statewide Agricultural Land Use Baseline 2015. http://doi.org/10.1017/CBO978 1107415324.004

[24] Ranschaert, E. R., Van Ooijen, P., McGinty, G. B., \& Parizel, P. M. (2016). Radiologists' usage of 
social media: results of the RANSOM Survey. Journal of Digital Imaging, (August 2016). http://doi.org/10.1007/s10278-016-9865-1

[25] Antheunis, M. L., Tates, K., \& Nieboer, T. E. (2013). Patients' and health professionals' use of social media in health care: Motives, barriers and expectations. Patient Education and Counseling, 92(3), 426-431.

http://doi.org/10.1016/j.pec.2013.06.020

[26] Rolls, K., Hansen, M., Jackson, D., \& Elliott, D. (2016). How health care professionals use social media to create virtual communities: an integrative review. Journal of Medical Internet Research, 18(6), e166.

[27] Creswell, J. W., \& Miller, D. L. (2000). Determining validity in qualitative inquiry. Theory into Practice, 39(3), 124-130.

[28] Lincoln, Y.S., \& Guba, E.G. (1985). Naturalistic inquiry. Newbury Park, CA: Sage.

[29] Stake, R. E. (1995). The art of case study research. Thousand Oaks, CA: Sage.

[30] Yin, R. K. (2013). Validity and generalization in future case study evaluations. Evaluation, 19(3), 321-332.

[31] Zakaria, N., \& Yusof, S. A. M. (2016). Understanding technology and people issues in hospital information system (HIS) adoption: Case study of a tertiary hospital in Malaysia. Journal of infection and public health, 9(6), 774-780.

[32] Kim, E., Fox, S., Moretti, M., Turner, M., Girard, T., \& Chan, S. Y. (2019). Motivations and Barriers Associated With Physician Volunteerism for an International Telemedicine Organization. Frontiers in public health, 7, 224.

[33] Choukas-Bradley, S., Giletta, M., Cohen, G. L., \& Prinstein, M. J. (2015). Peer influence, peer status, and prosocial behavior: An experimental investigation of peer socialization of adolescents' intentions to volunteer. Journal of Youth and Adolescence, 44(12), 2197-2210.

[34] Jiang, S. (2019). The relationship between faceto-face and online patient-provider communication: examining the moderating roles of patient trust and patient satisfaction. Health communication, 1-9.

[35] Fleming, L., \& Waguespack, D. (2005). Penguins, Camels, and Other Birds of a Feather: Brokerage, Boundary Spanning, and Leadership in Open Innovation Communities.(Free/Open Source Research Community).

[36] Akintola, O. (2010). What motivates people to volunteer? The case of volunteer AIDS caregivers in faith-based organizations in KwaZulu-Natal, South Africa. Health policy and planning, 26(1), 53-62.

[37] Sallam, A. A. A., Abdullah, S., Ramli, A. J., Hussin, N. S., Ahmad, Z., \& Bahari, A. (2018). Religiosity and Volunteering Intention among Undergraduate Malaysian Muslim Students. In MATEC Web of Conferences (Vol. 150, p. 05100). EDP Sciences. 